\title{
Numerical analysis of the impact of removing a corner column in a continuous slab-column structure in relation to the experimental model
}

\author{
Miroslaw Wieczorek ${ }^{1, *}$ \\ ${ }^{1}$ Silesian University of Technology, Faculty of Civil Engineering, Gliwice, Poland
}

\begin{abstract}
The paper presents the numerical analysis of the impact of removing a corner column on the behavior of a continuous slab-column structure. The model uses the minimal reinforcement amount compliant with Eurocodes. The basis for numerical modelling was the experimental research of a piece of a slab-column structure with the dimensions of $3.0 \times 3.0 \mathrm{~m}$ in column axes. The article includes a detailed description of the assumed conditions of the model support, the method of loading and reading of the results. The paper also compares the obtained results of numerical calculations with experimental results.
\end{abstract}

\section{Introduction}

Slab-column structures belong to the most common structural systems around the world, mainly due to simple calculation methods, virtually unlimited ability to create horizontal projections of floors, and simplicity of execution. However, the disadvantage of this type of structure is the low resistance to emergency situations most often induced by improper operation or accidental actions. The elements threatened with damage include columns which transfer vertical and horizontal loads and vertically loaded floor slabs. The paper presents the numerical simulation of a flat corner part of a slab following a sudden corner support removal. Simulations were based on experimental research described in [1].

\section{Characteristics of the models}

\subsection{Description of the experimental model}

In order to investigate the behavior of the corner part of a slab column structure after the removal of a support, the model of an actual structure was applied, carried out in the scale $1: 2$. The tested model was a nine-field reinforced concrete slab with the dimensions of $9300 \times 9300 \times 100 \mathrm{~mm}$, supported articulately on 16 columns (Fig. 1). The model was divided into parts with different arrangement of reinforcements and different types of reinforcements. Fig. 2 shows the arrangement of the reinforcement.

\footnotetext{
* Corresponding author: miroslaw.wieczorek.box@gmail.com
} 
a)

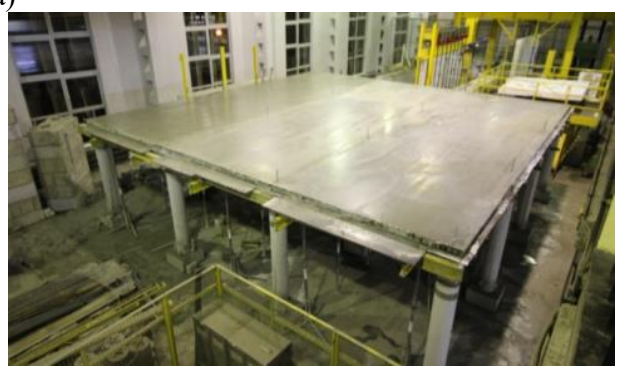

b)

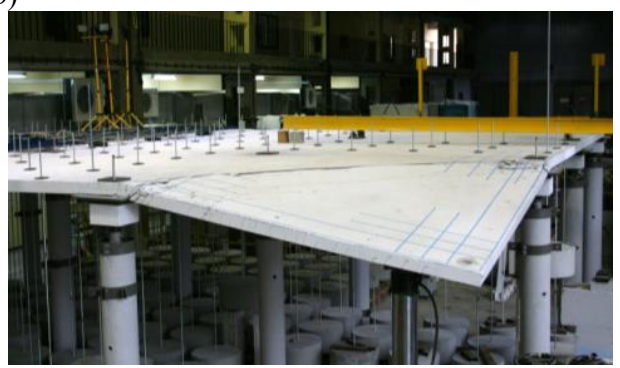

Fig. 1. View of the analyzed area of slab: a) before the test, b) after test.

The starting point for defining the model reinforcement was the assumption that bottom bars would be arranged with $200 \mathrm{~mm}$ spacings. Next, based on simplified static and strength calculations, the approximate amount of bottom and upper reinforcement in the remaining parts of the model was defined. Subsequently, the agreed amount of reinforcement was increased by adding peripheral and internal ties as required by EC1 [8] and ACI-318 [7] and using extra reinforcing bars in order to satisfy the conditions of bar spacing provided in [6].

a)

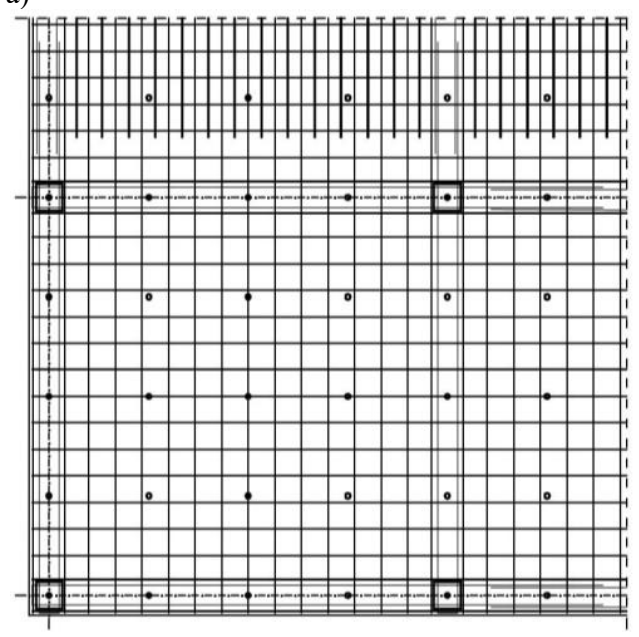

b)

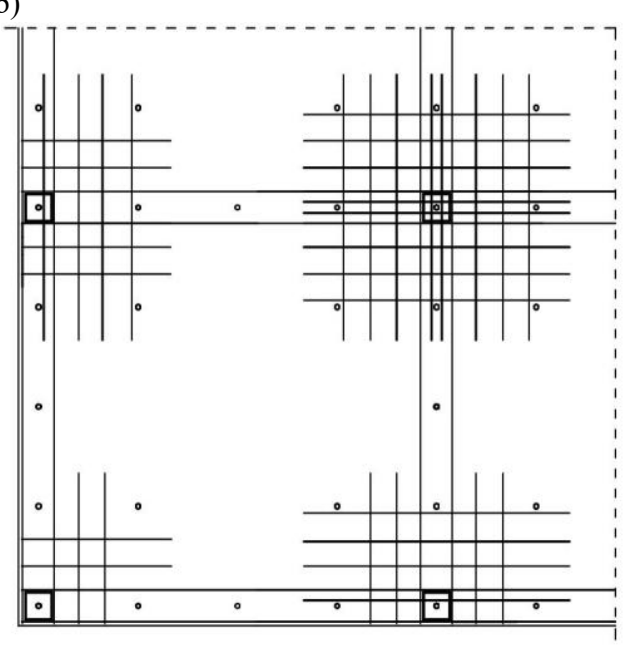

Fig. 2. Scheme of main reinforcement of the experimental model [1]: a) bottom reinforcement - span reinforcement $8 \mathrm{~mm}$ and integrity reinforcement $12 \mathrm{~mm}$; b) upper reinforcement - bars $8 \mathrm{~mm}, 10 \mathrm{~mm}$.

\subsection{Description of the numerical model}

In order to describe in more detail the mechanisms of destruction in the course of laboratory tests, attempts have been made to compare the obtained results of displacement of the upper surface of the slab with those obtained in numerical calculations.

Depending on the properties of numerical tools, various ways of modelling reinforced concrete elements may be applied. Paper [2] presents two of the most commonly used approaches to modelling the reinforcement in concrete - model with smeared reinforcement or discrete reinforcement. The selection of approach should depend on the level of detail required for calculations or the scope of results to be obtained. Models including the smeared reinforcement [2] are usually used for calculations of large structures where the general behavior of a structure is analyzed. With the discrete approach, reinforcement is usually 
modelled using bar-type elements (calculations only include the axial force present in the element) or beam-type elements (calculations also include bending and torsional moments) $[3,4]$.

Two programs were used for the numerical analysis: ANSYS and ABC-PŁYTA. In ABC-PŁYTA, the experimental model was represented with $15.0 \times 15.0 \mathrm{~cm}$ and $10.0 \mathrm{~cm}$ thick shell elements (in support axes, the dimensions of the finite element were two times smaller) (Fig. 3). The model reinforcement was adopted as smeared (Fig. 4). The calculation algorithms of ABC-PŁYTA are based on EC2 [6]. The material data assumed in calculations were defined following the standards $[8,9]$ - they are included in Table 1 and Table 2.

In these calculations it has been assumed that:

- the values concerning the thickness of the model and its dimensions coincide with those of the actual model,

- the scheme of the load of each model consisted of:

- a constant load (the dead load of the model) - distributed in a uniform manner,

- a varying load (hydraulic load) - concentrated loads.

The displacements of the slab surface obtained in numerical calculations are presented in Fig. 7.

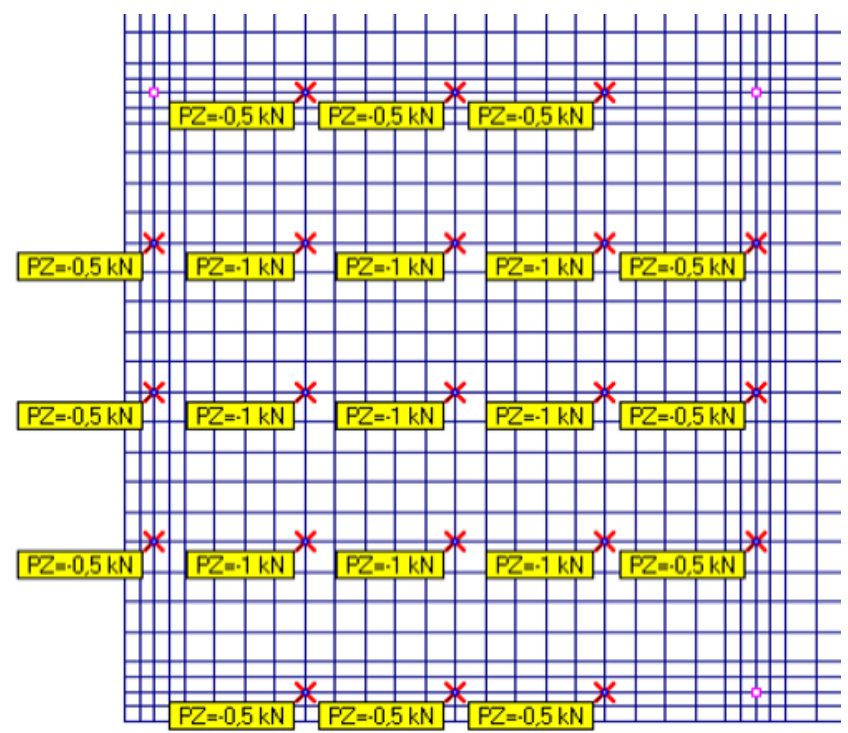

Fig. 3. View of the model developed in ABC-PŁYTA [5] - scheme of the alternating load - part of the model (first step of loading).

Table 1. Mechanical parameters of rough bars, tested in compliance with PN-EN 10002-1:1998.

\begin{tabular}{|c|c|c|c|c|}
\hline $\begin{array}{c}\text { Diameter } \\
\text { of the bar } \\
\boldsymbol{\varnothing}[\mathbf{m m}]\end{array}$ & $\begin{array}{c}\text { Module of elasticity } \\
\boldsymbol{E}[\mathbf{G P a}]\end{array}$ & $\begin{array}{c}\text { Yield strength } \\
\boldsymbol{f}_{\boldsymbol{y} \boldsymbol{k}}[\mathbf{M P a}]\end{array}$ & $\begin{array}{c}\text { Tensile strength } \\
\boldsymbol{f}_{\boldsymbol{t}}[\mathbf{M P a}]\end{array}$ & $\begin{array}{c}\text { Total elongation } \\
\text { at maximum force } \\
\boldsymbol{\varepsilon}_{\boldsymbol{u}}[\boldsymbol{\%}]\end{array}$ \\
\hline 8 & 191.852 & 526.8 & 604.4 & 14.91 \\
\hline 10 & 199.138 & 561.1 & 625.8 & 13.8 \\
\hline 12 & 199.242 & 601.2 & 714.2 & 11.8 \\
\hline
\end{tabular}


Table 2. Mechanical parameters of concrete investigated in compliance with PN-EN 12390-3:2002.

\begin{tabular}{|c|c|c|c|}
\hline $\begin{array}{c}\text { Module of elasticity } \\
\boldsymbol{E}_{c m}[\mathbf{G P a}]\end{array}$ & $\begin{array}{c}\text { Compressive Strength } \\
\boldsymbol{f}_{c, c y l}[\mathrm{MPa}]\end{array}$ & $\begin{array}{c}\text { Compressive Strength } \\
\boldsymbol{f}_{c, \text { cube }}[\mathrm{MPa}]\end{array}$ & $\begin{array}{c}\text { Tensile strength } \\
\boldsymbol{f}_{c m}[\mathrm{MPa}]\end{array}$ \\
\hline 41.2 & 64.2 & 79.5 & 4.07 \\
\hline
\end{tabular}

a)

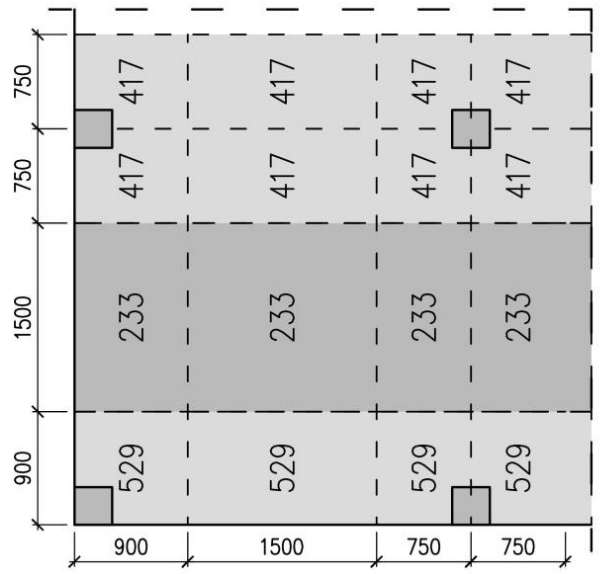

c)

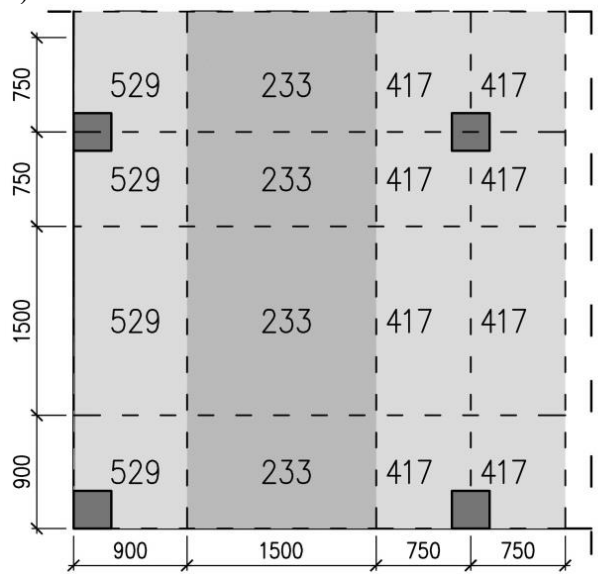

b)

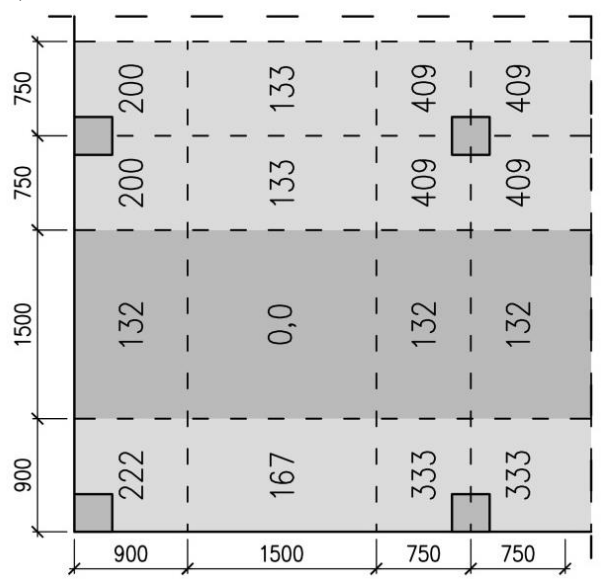

d)

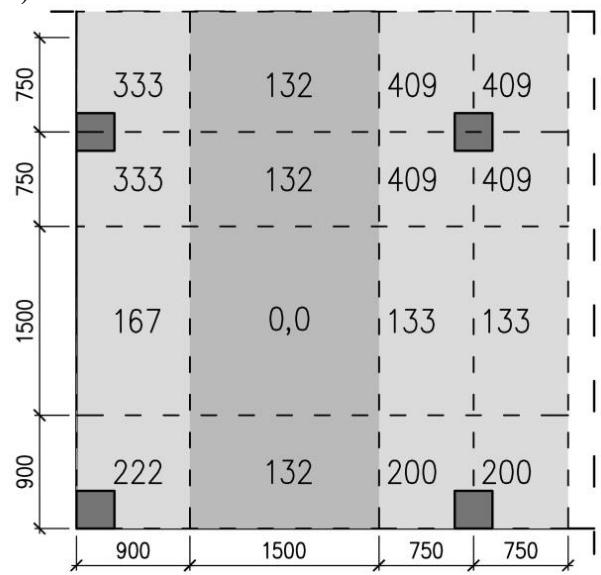

Fig. 4. Amount of reinforcement assumed in ABC-PŁYTA in $\mathrm{mm}^{2} / \mathrm{m} \mathrm{[6]:} \mathrm{a)} \mathrm{bottom} \mathrm{reinforcement}$ in X direction (10 $\mathrm{mm}$ cover), b) bottom reinforcement in Y direction (10 $\mathrm{mm}$ cover), c) upper reinforcement in $\mathrm{X}$ direction (10 $\mathrm{mm}$ cover), d) upper reinforcement in $\mathrm{Y}$ direction (10 $\mathrm{mm}$ cover).

The second numerical model was developed in ANSYS. Similarly, as in the investigations $[11,12,13]$, two kinds of finite elements were applied, viz. a solid element Solid 65 and a bar element Beam 188. Both of them were assigned with parameters according to Table 3. The Solid 65 element was used to model the concrete [13]. This element has eight nodes with three degrees of freedom at each node: translations in the nodal $\mathrm{x}, \mathrm{y}$, and $\mathrm{z}$ directions. The element is capable of plastic deformation, cracking in three orthogonal directions, and crushing. Due to the calculation capabilities, the program represents only $1 / 4$ of the entire model with symmetry planes assumed on two edges. Solid 65 finite elements had 
the dimensions of $5.0 \times 5.0 \mathrm{~cm}$ and were $1.0 \mathrm{~cm}$ high. Fig. 5 presents the view of the model. The method and values of the load applied corresponded to the numerical model from ABC-PŁYTA. The obtained displacement results of the slab surface were presented in Fig. 7.

Table 3. Mechanical parameters of concrete and steel investigated in compliance with PN-EN 12390-3:2002 and PN-EN 10002-1:1998.

\begin{tabular}{|c|c|c|c|c|c|c|c|c|}
\hline $\begin{array}{l}\text { Element } \\
\text { tvpe }\end{array}$ & & & Mat & erial prope & rties & & & \\
\hline \multirow{6}{*}{ Solid65 } & $\begin{array}{l}\text { Linear } \\
\text { Isotropic }\end{array}$ & EX & 41.2 & $\mathrm{GPa}$ & PR & $X Y$ & & \\
\hline & \multirow{3}{*}{$\begin{array}{l}\text { Multilinear } \\
\text { Isotropic }\end{array}$} & & Point 1 & Point 2 & Point 3 & Point 4 & Point 5 & Point 6 \\
\hline & & Strain $[\mathrm{mm} / \mathrm{mm}]$ & 0.00020 & 0.00035 & 0.0005 & 0.0010 & 0.0015 & 0.0020 \\
\hline & & Stress $[\mathrm{MPa}]$ & 13.70 & 23.98 & 31.95 & 52.87 & 61.24 & 64.39 \\
\hline & \multirow{2}{*}{ Concrete } & \multicolumn{2}{|c|}{$\begin{array}{l}\text { Shear transfer coefficient } \\
\text { for open crack }\end{array}$} & 0.3 & \multicolumn{3}{|c|}{$\begin{array}{l}\text { Shear transfer coefficient } \\
\text { for open crack }\end{array}$} & 1 \\
\hline & & \multicolumn{2}{|c|}{$\begin{array}{c}\text { Uniaxial tensile cracking } \\
\text { stress }\end{array}$} & $4.07 \mathrm{MPa}$ & \multicolumn{3}{|c|}{ Uniaxial crushing stress } & -1 \\
\hline Solid45 & $\begin{array}{c}\text { Linear } \\
\text { Isotropic }\end{array}$ & $\mathrm{EX}[\mathrm{GPa}]$ & \multicolumn{2}{|c|}{200} & \multicolumn{2}{|c|}{ PRXY } & \multicolumn{2}{|c|}{0,3} \\
\hline \multirow{13}{*}{ Beam 188} & $\begin{array}{l}\text { Linear } \\
\text { Isotropic }\end{array}$ & $\mathrm{EX}[\mathrm{GPa}]$ & \multicolumn{2}{|c|}{193.20} & & $X Y$ & \multicolumn{2}{|c|}{0,3} \\
\hline & \multirow{12}{*}{$\begin{array}{l}\text { Multilinear } \\
\text { Isotropic } \\
\text { Hardening }\end{array}$} & \multicolumn{7}{|c|}{ Diameter $8.0 \mathrm{~mm}$} \\
\hline & & & Point 1 & Point 2 & Point 3 & Point 4 & Point 5 & Point 6 \\
\hline & & Strain $[\mathrm{mm} / \mathrm{mm}]$ & 0.275 & 3.5 & 4.0 & 6.0 & 8.0 & 14,91 \\
\hline & & Stress [MPa] & 526.8 & 536.8 & 550.3 & 582.7 & 599.3 & 604.4 \\
\hline & & & & Diamete & $\mathrm{r} 10.0 \mathrm{mr}$ & & & \\
\hline & & & Point 1 & Point 2 & Point 3 & Point 4 & Point 5 & Point 6 \\
\hline & & Strain $[\mathrm{mm} / \mathrm{mm}]$ & 0.282 & 3.4 & 4.0 & 6.0 & 8.0 & 13.8 \\
\hline & & Stress [MPa] & 561.1 & 570.6 & 575.7 & 601.3 & 615.4 & 625.8 \\
\hline & & & & Diamete & $12.0 \mathrm{mr}$ & & & \\
\hline & & & Point 1 & Point 2 & Point 3 & Point 4 & Point 5 & Point 6 \\
\hline & & Strain $[\mathrm{mm} / \mathrm{mm}]$ & 0.301 & 3.1 & 4.0 & 6.0 & 8.0 & 11.8 \\
\hline & & Stress [MPa] & 601.2 & 612.8 & 627.3 & 672.4 & 699.5 & 714.2 \\
\hline
\end{tabular}




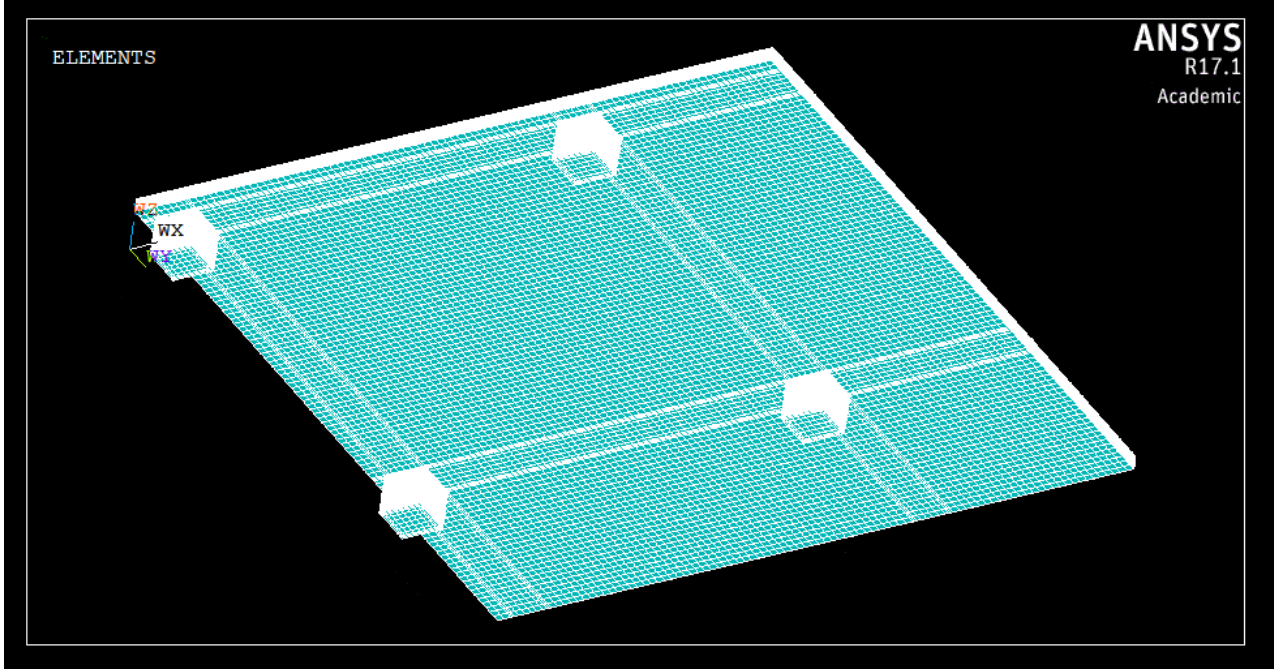

Fig. 5. View of the numerical model prepared in ANSYS.

\section{Analysis of the results}

The main parameter measured in the course of experimental research were the displacements of the upper surface of the model, registered at each subsequent loading step. Fig. 7 presents the graph of displacements of the upper surface of the investigated model at the moment of failure. Fig. 6 compares the results of experimental measurements with the results of numerical calculations. Details are presented in Table 4.

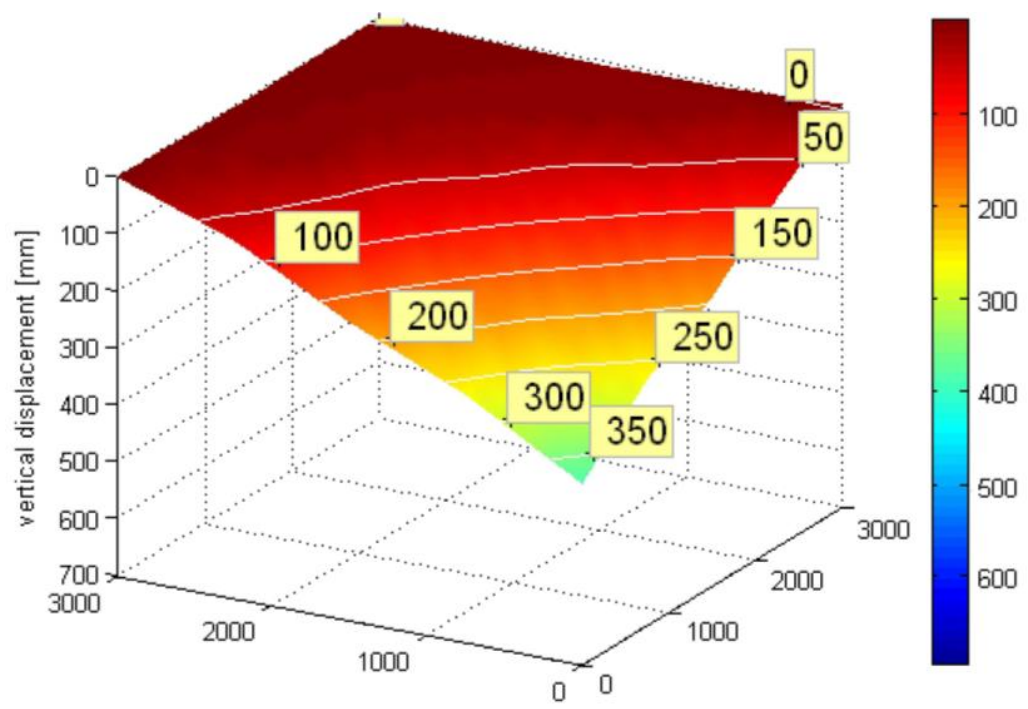

Fig. 6. Displacements of the upper surfaces of the model (results of laboratory tests) $[1,5]$. 
a)

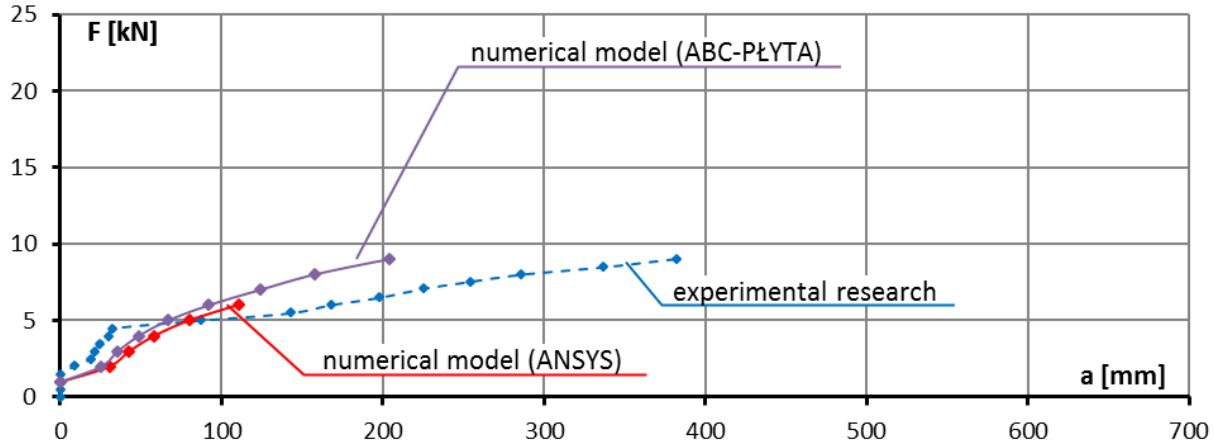

b)

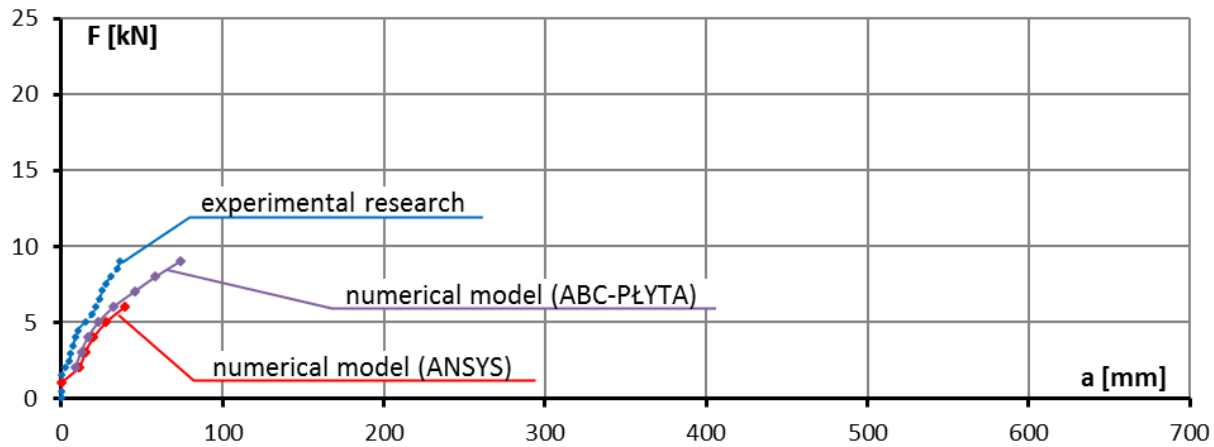

Fig. 7. Displacements of the upper surfaces of the models (results of laboratory tests and numerical calculations): a) displacement at the end of the corner, b) displacement in the centre of the field.

Table 4. Values of displacement at the moment of the model failure.

\begin{tabular}{|c|c|c|c|}
\hline \multirow{2}{*}{ Measuring point } & \multicolumn{3}{|c|}{ Values of displacement [mm] } \\
\cline { 2 - 4 } & $\begin{array}{c}\text { Experimental } \\
\text { research }\end{array}$ & $\begin{array}{c}\text { Numerical model } \\
\text { (ABC-PLYTA) }\end{array}$ & $\begin{array}{c}\text { Numerical model } \\
\text { (ANSYS) }\end{array}$ \\
\hline $\begin{array}{c}\text { Displacement in the centre } \\
\text { of the field at load of } 6.2 \mathrm{kN}\end{array}$ & 21.3 & 32.5 & $\begin{array}{c}39.2 \\
\text { then no solution convergence }\end{array}$ \\
\hline $\begin{array}{c}\text { Displacement at the end } \\
\text { of the corner at load of } 6.2 \mathrm{kN}\end{array}$ & 167.5 & 92.14 & $\begin{array}{c}110.5 \\
\text { than no solution convergence }\end{array}$ \\
\hline $\begin{array}{c}\text { Displacement in the centre } \\
\text { of the field at load of } 9.0 \mathrm{kN} \\
\text { (end of experimental research) }\end{array}$ & 36.4 & 73.5 & - \\
\hline $\begin{array}{c}\text { Displacement at the end } \\
\text { of the corner at load of } 9.0 \mathrm{kN} \\
\text { (end of experimental research) }\end{array}$ & 385 & 207 & - \\
\hline
\end{tabular}


The comparison of the results of the experimental research and numerical calculations revealed substantial differences between the values obtained which could have resulted from:

- the adopted methodology of introducing loads and boundary conditions in numerical models

In the experimental research, the support was removed only after loading of the test model. In the case of numerical models, due to technical limitations, the support was removed as first, followed by application of loads. In the experimental model, the slab corner shifted by merely $3.0 \mathrm{~mm}$ following the support removal. For this reason, it was assumed that the adopted method of load application shall have negligible impact, which was confirmed by the comparison of results at the first level of loading.

- significantly higher, global stiffness of numerical models compared to the experimental model

Based on standards $[3,4]$, this can be explained with the fact that in numerical programs, deformation is related to the simultaneous strain of all finite elements. In fact, with light loads, minor fractures could emerge at a certain distance from one another, slowly increasing in width without any new cracks in between. However, it should be noted that using both programs brought similar displacement values for loads up to $6.2 \mathrm{kN}$ at which no solution convergence was attained in ANSYS.

- the nature of displacements obtained in the course of experimental research and numerical calculations

Displacements obtained in the experimental model resulted from its failure mechanism. A typical scheme of cantilever failure was obtained in which the destroyed part of the model was a flat plain. In numerical simulations, the analyzed part of the slab took the shape of an inverted shell.

- values of material parameters adopted in calculations

Although the material research was carried out according to standards $[8,9]$, the strength values measured on samples might have been different from the ones in the experimental model because of the curing conditions of concrete.

\section{Summary}

Numerical modelling of experimental research is one of the many tools allowing to support the research process of (e.g. by reducing the cost of the research by limiting the number of research elements or capability to perform measurements in hard to reach locations). The analysis of results obtained during a numerical simulation must be firstly verified using the results of the experimental research. The numerical analysis did not produce a very good representation of the behavior of the corner part of a slab-column structure following the corner support removal, although two different ways of reinforcement modelling were used: the smeared reinforcement in ABC-PŁYTA and the discrete reinforcement in ANSYS. The differences between the numerical simulation in ANSYS and the experimental research could also have resulted from the lack of detailed investigations of concrete involving biaxial and triaxial compressive strength of concrete which would need to be defined during material research. Because of the lack of such research, recalculation formulas recommended by ANSYS were employed. However, attention should be paid to the fact that in some cases $[3,4]$ using these formulas for determining biaxial and triaxial compressive strength of concrete allows to obtain very good compatibility of numerical and experimental models. In the case of ABC-PŁYTA, the satisfactory compatibility of the analyzed results was also not obtained, what can be caused by the very simplistic theoretical models implemented in the program used for describing the behavior of the material. Nevertheless, it has to be noted that the results obtained from both programs were very similar and constituted a good representation the behavior of the experimental model in the first stage of the research. 


\section{References}

1. M. Wieczorek: Procedia Engineering, 57, (2013)

2. F.A. Tavarez, M.E. Plesha: International Journal for Numerical Methods in Engineering, 70, 4 (2006)

3. T. Kang, J. Wallace, K. Elwood: Journal of Structural Engineering, 135, 2 (2009)

4. A.J. Wolański: Flexural behavior of reinforced and pre-stressed concrete beams using finite element analysis, Master's Thesis, Marquette University, Milwaukee, Wisconsin, (2004)

5. M. Wieczorek: Load capacity of slab-column structure in case of emergency destruction of the corner support. Ph.D. thesis, Silesian Technical University, Poland (2012)

6. EN 1992-1-1:2004/AC, Eurocode 2: Design of concrete structures - Part 1-1: General rules and rules for buildings (2010)

7. ACI 318-11 Building Code Requirements for Structural Concrete and Commentary, American Concrete Institiute, Detroit, United State America (2011)

8. EN 1991-1-7:2006/AC Eurocode 1: Actions on structures - Part 1-7: General actions Accidental actions (2010)

9. PN-EN 10002-1:1998: Tensile testing of metallic materials. Method of test at ambient temperature (1998)

10. PN-EN 12390-3:2002: Testing hardened concrete. Compressive strength of test specimens (2002)

11. A.F. Barbosa: A study of models for nonlinear finite element analysis of concrete structures (Dissertation for attainment of Master Degree), Federal University of Minas Gerais (1997)

12. M.Sh. Mahmood, A.M. Ibrahim: European Journal of Scientific Research, 30, 4 (2009)

13. SAS ANSYS 17.1 Finite Element Analysis System, SAS IP, Inc. (2018) 